\title{
Corneal Segmentation Analysis Increases Glaucoma Diagnostic Ability of Optic Nerve Head Examination, Heidelberg Retina Tomograph's Moorfield's Regression Analysis, and Glaucoma Probability Score
}

\author{
F. Saenz-Frances, L. Jañez, C. Berrozpe-Villabona, \\ L. Borrego-Sanz, L. Morales-Fernández, A. Acebal-Montero, \\ C. D. Mendez-Hernandez, J. M. Martinez-de-la-Casa, \\ E. Santos-Bueso, J. Garcia-Sanchez, and J. Garcia-Feijoo
}

Hospital Clínico Universitario San Carlos, 28040 Madrid, Spain

Correspondence should be addressed to F. Saenz-Frances; federicosaenzfrancessb@gmail.com

Received 1 March 2015; Accepted 5 May 2015

Academic Editor: Edward Manche

Copyright (C) 2015 F. Saenz-Frances et al. This is an open access article distributed under the Creative Commons Attribution License, which permits unrestricted use, distribution, and reproduction in any medium, provided the original work is properly cited.

Purpose. To study whether a corneal thickness segmentation model, consisting in a central circular zone of 1 mm radius centered at the corneal apex (zone I) and five concentric rings of $1 \mathrm{~mm}$ width (moving outwards: zones II to VI), could boost the diagnostic accuracy of Heidelberg Retina Tomograph's (HRT's) MRA and GPS. Material and Methods. Cross-sectional study. 121 healthy volunteers and 125 patients with primary open-angle glaucoma. Six binary multivariate logistic regression models were constructed (MOD-A1, MOD-A2, MOD-B1, MOD-B2, MOD-C1, and MOD-C2). The dependent variable was the presence of glaucoma. In MOD-A1, the predictor was the result (presence of glaucoma) of the analysis of the stereophotography of the optic nerve head (ONH). In MOD-B1 and MOD-C1, the predictor was the result of the MRA and GPS, respectively. In MOD-B2 and MOD-C2, the predictors were the same along with corneal variables: central, overall, and zones I to VI thicknesses. This scheme was reproduced for model MOD-A2 (stereophotography along with corneal variables). Models were compared using the area under the receiver operator characteristic curve (AUC). Results. MOD-A1-AUC: 0.771; MOD-A2-AUC: 0.88; MOD-B1-AUC: 0.736; MOD-B2-AUC: 0.845; MOD-C1-AUC: 0.712; MOD-C2-AUC: 0.838. Conclusion. Corneal thickness variables enhance ONH assessment and HRT's MRA and GPS diagnostic capacity.

\section{Introduction}

Whereas stereoscopic assessment of the optic nerve head $(\mathrm{ONH})$ remains the gold standard of structural glaucoma diagnosis, many new automatic devices have been developed to either improve the diagnostic accuracy or help ophthalmic practitioners in routine clinical practice [1-19]. Amongst them, the Heidelberg Retina Tomograph (HRT) has proven to be a very useful tool despite its limitations [20-25].

Although broad evidence suggests that central corneal thickness (CCT) is both an IOP measurement confounder and an independent risk factor for developing primary openangle glaucoma (POAG), most of the literature regarding this matter only takes into account the very centre of the cornea [25-48]. In order to study noncentral corneal thickness differences between healthy subjects and patients suffering from POAG, we developed a ring-shaped corneal segmentation model [49] which suggested that these differences indeed exist. Moreover, in spite of not being a diagnostic tool in itself, our pattern showed some diagnostic capacity between cases of POAG and healthy controls [49]. 
The purpose of this study is to establish if the addition of the corneal thickness variables generated through our segmentation model could improve the diagnostic accuracy of the HRT results.

\section{Material and Methods}

We performed a cross-sectional study in 121 healthy volunteers and 125 patients with primary open-angle glaucoma. The patients were recruited from the Glaucoma Unit of the Hospital Clínico San Carlos, Madrid (Spain), and control subjects among the patients' companions and hospital staff. The study protocol was approved by our institution's review board and complied with the guidelines of the Declaration of Helsinki. Informed consent was obtained from each participant before inclusion in the study. All the study participants were Caucasian. Eyes were considered to be glaucomatous if they had shown abnormal results in at least three consecutive visual field exams (Octopus TOP-G1X) and if there was evidence of glaucomatous damage as determined by the appearance of the $\mathrm{ONH}$ and retinal nerve fiber layer thickness (RNFL) as determined using Heidelberg Spectralis Optic Coherence Tomograph (OCT) and stereophotographs of the ONH. Only patients with early and moderate glaucoma (according to Hodapp, Parrish, and Anderson's Classification modified for Octopus perimetry) were eligible for the study. The glaucoma patients were required to show gonioscopic evidence of a normal and open angle. Subjects with nonprimary open-angle glaucoma (e.g., pseudoexfoliation, pigment dispersion, and neovascularization) were excluded. It was accordingly checked that control subjects had an IOP < $21 \mathrm{mmHg}$, a normal visual field, and a nonglaucomatous appearing optic disc and RNFL thickness. With regard to Moorfield's regression analysis (MRA) and glaucoma probability score (GPS), subjects showing a borderline diagnosis of glaucoma were excluded.

General exclusion criteria were a spherical equivalent greater than 5 diopters, or 3 or more diopters of astigmatism, a best corrected visual acuity lower than 20/25, opacities in the cornea or lens impairing optic nerve head visualization, and alterations in optic nerve head morphology, such as oblique discs or peripapillary atrophy. We also excluded subjects who had undergone prior eye surgery and those whose visual field defects were of causes other than glaucoma (e.g., demyelinating disease, nonglaucomatous neuropathy, or a central nervous system disorder). If both eyes of a patient or subject fulfilled all the inclusion and exclusion criteria, the eye to be examined was determined through an automatic randomization procedure (http://www.randomization.com).

All the study participants underwent a Pentacam (Pentacam, Oculus USA) examination, ultrasound pachymetry (Dicon P55, Paradigm Medical Industries Inc., Salt Lake City, UT, USA), a Confocal scanning laser tomography (HRT-3, Heidelberg Engineering, Germany), and a Heidelberg Spectralis RNFL thickness OCT (Heidelberg Spectralis, Heidelberg Engineering, Germany). Being noncontact procedures, the Pentacam, HRT, and OCT evaluations were performed first. The order in which the remaining exploration was performed was established through an automatic

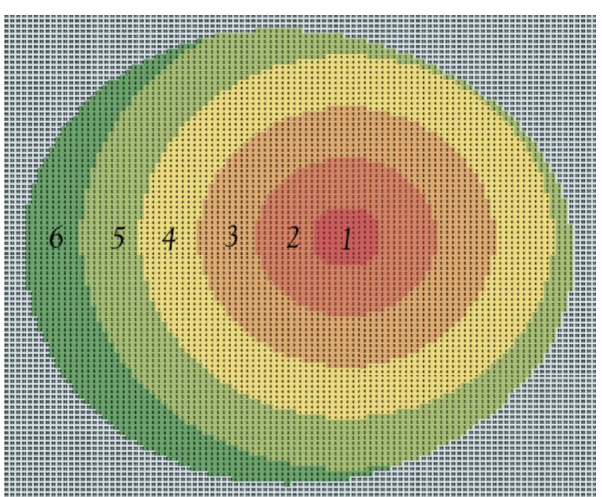

FIgURE 1: Corneal thickness segmentation scheme into virtual circular zones concentric with the corneal apex (1 to 6 denote zone I to zone VI, resp.).

randomization procedure (http://www.randomization.com). Using the pachymetric maps generated by the Pentacam (this instrument makes thickness measurements across the entire cornea perpendicular to its surface separated by a distance of $1 \mu \mathrm{m}$ ), we virtually segmented the cornea into a central circular zone of radius of $1 \mathrm{~mm}$ (designated zone I) centered at the corneal apex (this is the point of maximum curvature or height, typically temporal to the centre of the pupil) and several concentric rings of $1 \mathrm{~mm}$ width each with the same centre (5 rings until the corneal limbus denoted zones II, III, IV, V, and VI, resp., moving outward from the centre) (Figure 1).

Six binary multivariate logistic regression models were constructed (denoted as MOD-A1, MOD-A2, MOD-B1, MOD-B2, MOD-C1, and MOD-C2, resp.). In all of them, the dependent variable was the presence (or not) of glaucoma. In the MOD-A1 model the predictor was the result of the analysis of the stereophotography of the optic nerve head (ONH) by an examiner expert in ophthalmology (dichotomous result: glaucoma or not) (the examiner was masked to those who establish the diagnosis of glaucoma or not of the members of the sample according the comprehensive examination described before). In the MOD-B1 and MOD$\mathrm{C} 1$ models the predictor was the result of the MRA and GPS, respectively (dichotomous result: glaucoma or not, as the borderline cases were an exclusion criterion), adjusted for age and disc size (as determined by the HRT); the presence of interactions between age and disc size with the result of MRA and GPS was also studied. In the MOD-B2 and MOD-C2 models the predictors were the result of MRA and GPS, respectively (dichotomous result: glaucoma or not, as the borderline cases were an exclusion criterion), but, in these models, along with corneal variables, central corneal thickness (CCT) (as determined by ultrasound pachymetry), overall corneal thickness (OT), and the thicknesses of zones created with the corneal segmentation (zone I to zone VI) (all adjusted for age and disc size), interactions between age and disc size with all the predictors were studied. The same scheme was reproduced for model MOD-A2: the predictors were the result of the analysis of the stereophotography of the optic nerve head $(\mathrm{ONH})$ by an expert in glaucoma 
TABLE 1: Mean and standard deviation (std. deviation) of the corneal variables.

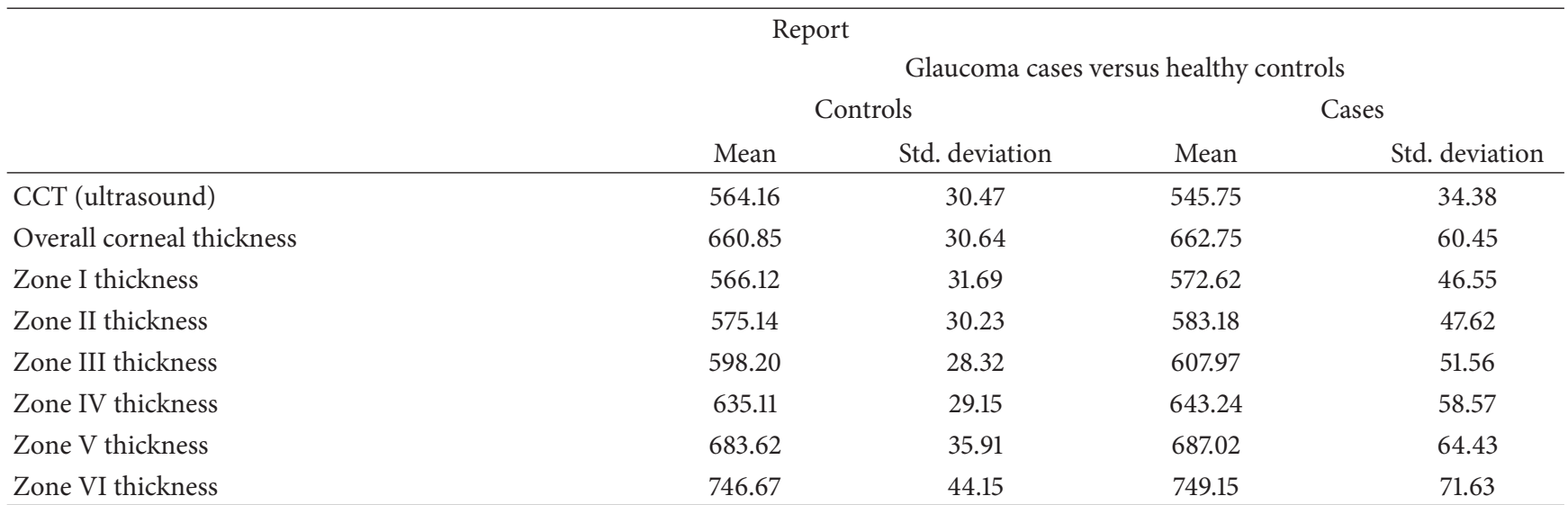

(dichotomous result: glaucoma or not) along with the corneal variables mentioned before (for MOD-B2 and MOD-C2).

We determined the discriminating capacity between glaucoma and normality of each predictor in each model determining its odds ratio (OR) of suffering from glaucoma.

Models were compared using the area under the receiver operator characteristic (ROC) curve (AUC) and the Nagelkerke- $R^{2}$.

Sensitivity, specificity, positive predictive value, and negative predictive value of detecting glaucoma (cutoff of 0.5 ) were also determined for each model.

Statistical difference between the AUC of each pair of models (MOD-A1 and MOD-A2, MOB-B1 and MOD-B2, and MOD-C1 and MOD-C2, resp.) was established performing several DeLong's tests for two correlated ROC curves (one test for each pair).

The influence on the diagnostic accuracy of each model (as a dichotomous variable: right classification or wrong classification) of the stage of glaucoma was also assessed through several logistic univariate regression models being the predictor the stage of glaucoma (three categories according to Hodapp, Parrish, and Anderson's classification: normality, early stage glaucoma, and moderate glaucoma, as severe glaucoma was an exclusion criterion).

\section{Results}

The two groups examined in this cross-sectional study were 121 eyes of 121 healthy subjects and 125 eyes of 125 patients with POAG.

Table 1 provides the means and standard deviations (sd) of the corneal variables recorded.

Mean age was 64.25 years (sd: 13.71$)$; mean disc size was 2.09 (sd: 0.495).

The normal distribution of data was confirmed by the Kolmogorov-Smirnov and Shapiro-Wilk tests.

MOD-A1 model revealed that the exam of the $\mathrm{ONH}$ by an expert examiner exhibits significant diagnosis ability for glaucoma $(\mathrm{OR}=4.83$; 95\% CI: $1.23-15.44)$. No significant interaction between age or disc size and the result of the examiner arose. AUC of this model was 0.771 (95\%

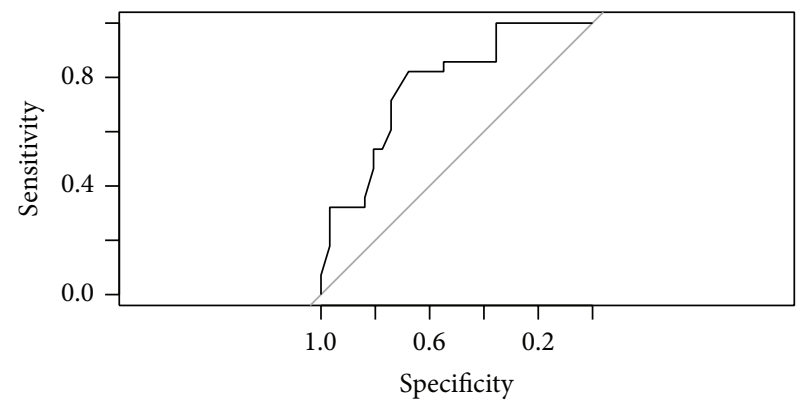

FIGURE 2: ROC curve for model MOD-A1.

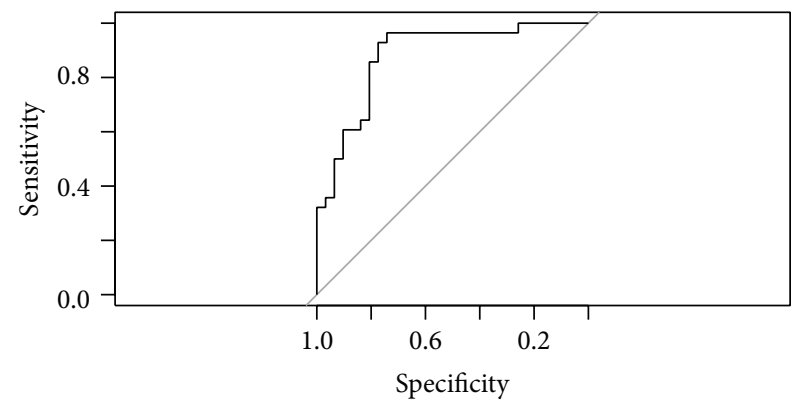

FIGURE 3: ROC curve for model MOD-A2.

CI: $0.651-0.891$ ). Sensitivity is $67.86 \%$; specificity is $74.19 \%$. Nagelkerke $R^{2}$ is $29,01 \%$. Figure 2 presents the ROC curve for this model.

Including corneal variables as predictors (MOD-A2) along with MRA outcome results in a furtherance of the diagnostic capacity of MOD-A1: $\mathrm{OR}=9.43$; 95\% CI: 5.11-12.81. Apart from MRA, other predictors showed discriminating capacity between POAG and normality (Table 2). AUC of this model was 0.88 (95\% CI: 0.791-0.969). Sensitivity is 78.57\%; specificity is $80.65 \%$. Nagelkerke $R^{2}$ is $52.14 \%$. Figure 3 presents the ROC curve for this model.

MOD-B1 revealed that also MRA outcome has significant diagnosis capability for glaucoma: $\mathrm{OR}=2.15$; 95\% CI: $1.08-$ 6.04. No significant interaction between age or disc size 
TABLE 2: Parameters showing the diagnostic ability of each significant variable in each model, respectively, (OR: odds ratio) and the diagnostic capacity of each model (sensitivity, specificity, positive and negative predictive values, AUC of ROC curves, and Nagelkerke $R^{2}$ ).

\begin{tabular}{|c|c|c|c|c|c|c|c|c|c|c|}
\hline \multirow[b]{2}{*}{ Model } & \multirow{2}{*}{$\begin{array}{l}\text { Significant } \\
\text { predictors }\end{array}$} & \multirow[b]{2}{*}{ OR } & \multicolumn{2}{|c|}{ OR 95\% CI } & \multirow[b]{2}{*}{ AUC } & \multirow[b]{2}{*}{$\begin{array}{c}\text { Sensitivity } \\
(\%)\end{array}$} & \multirow[b]{2}{*}{$\begin{array}{c}\text { Specificity } \\
(\%)\end{array}$} & \multirow{2}{*}{$\begin{array}{l}\text { Positive } \\
\text { predictive } \\
\text { value (\%) }\end{array}$} & \multirow{2}{*}{$\begin{array}{l}\text { Negative } \\
\text { predictive } \\
\text { value (\%) }\end{array}$} & \multirow{2}{*}{$\begin{array}{l}\text { Nagelkerke } \\
R^{2}(\%)\end{array}$} \\
\hline & & & $\begin{array}{l}\text { Lower } \\
\text { bound }\end{array}$ & $\begin{array}{l}\text { Higher } \\
\text { bound }\end{array}$ & & & & & & \\
\hline $\mathrm{A} 1$ & $\begin{array}{l}\text { ONH } \\
\text { assessment }\end{array}$ & 4.83 & 1.23 & 15.44 & 0.711 & 67.86 & 74.19 & 70.37 & 71.87 & 29.01 \\
\hline \multirow{6}{*}{$\mathrm{A} 2$} & $\begin{array}{l}\text { ONH } \\
\text { assessment }\end{array}$ & 9.43 & 5.11 & 12.81 & \multirow{6}{*}{0.88} & \multirow{6}{*}{78.57} & \multirow{6}{*}{80.65} & \multirow{6}{*}{78.71} & \multirow{6}{*}{84.14} & \multirow{6}{*}{52.14} \\
\hline & Zone I & 0.94 & 0.098 & 0.97 & & & & & & \\
\hline & Zone III & 1.33 & 1.19 & 1.49 & & & & & & \\
\hline & Zone V & 1.1 & 1.01 & 1.13 & & & & & & \\
\hline & Zone VI & 1.2 & 1.19 & 1.28 & & & & & & \\
\hline & OT & 0.85 & 0.69 & 0.87 & & & & & & \\
\hline B1 & $\begin{array}{l}\text { ONH } \\
\text { assessment }\end{array}$ & 2.15 & 1.08 & 6.04 & 0.736 & 64.29 & 73.28 & 69.23 & 69.69 & 22.74 \\
\hline \multirow{3}{*}{ B2 } & $\begin{array}{l}\text { ONH } \\
\text { assessment }\end{array}$ & 2.79 & 1.11 & 7.88 & \multirow{3}{*}{0.845} & \multirow{3}{*}{71.43} & \multirow{3}{*}{81.75} & \multirow{3}{*}{76.92} & \multirow{3}{*}{75.76} & \multirow{3}{*}{44.92} \\
\hline & Zone I & 0.97 & 0.94 & 0.99 & & & & & & \\
\hline & OT & 0.98 & 0.96 & 0.99 & & & & & & \\
\hline $\mathrm{C} 1$ & $\begin{array}{l}\text { ONH } \\
\text { assessment }\end{array}$ & 1.36 & 1.05 & 4.8 & 0.712 & 67.86 & 74.19 & 65.52 & 70.01 & 20.02 \\
\hline \multirow{3}{*}{$\mathrm{C} 2$} & $\begin{array}{l}\mathrm{ONH} \\
\text { assessment }\end{array}$ & 1.63 & 1.09 & 3.28 & \multirow{3}{*}{0.838} & \multirow{3}{*}{78.57} & \multirow{3}{*}{80.65} & \multirow{3}{*}{75.11} & \multirow{3}{*}{75.41} & \multirow{3}{*}{44.07} \\
\hline & Zone I & 0.97 & 0.95 & 0.98 & & & & & & \\
\hline & OT & 0.89 & 0.76 & 0.95 & & & & & & \\
\hline
\end{tabular}

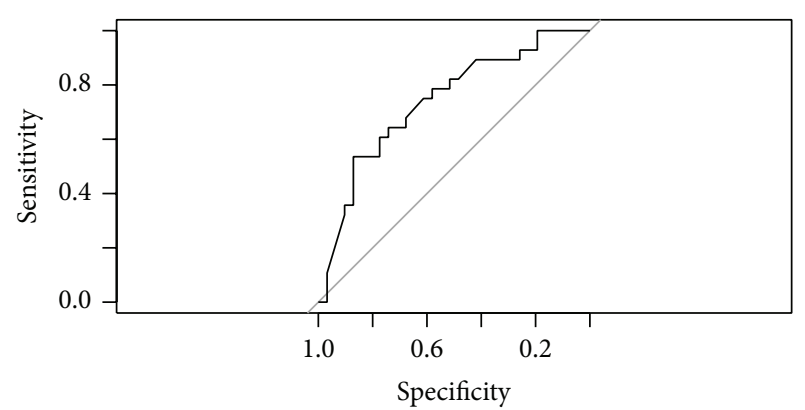

FIGURE 4: ROC curve for model MOD-B1.

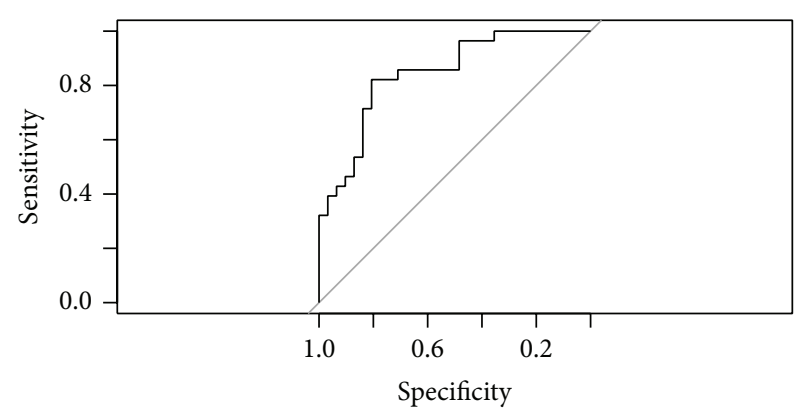

Figure 5: ROC curve for model MOD-B2. and the result of Moorfield's regression analysis arose. AUC of this model was 0.736 (95\% CI: 0.61-0.739). Sensitivity is $64.29 \%$; specificity is $73.28 \%$. Nagelkerke $R^{2}$ is $22.74 \%$. Figure 4 presents the ROC curve for this model.

MOD-B2 results present the effect of including the corneal variables along with MRA outcome: an increase of the diagnostic capacity of MOD-B1: OR $=2.79$; 95\% CI: 1.11-7.88. Apart from MRA, other predictors showed discriminating capacity between POAG and normality (Table 2). AUC of this model was 0.845 (95\% CI: $0.746-0.943)$. Sensitivity is $71.43 \%$; specificity is $81.75 \%$. Nagelkerke $R^{2}$ is $44,92 \%$. Figure 5 presents the ROC curve for this model.

MOD-C1 proved that GPS outcome has also significant diagnosis capability for glaucoma: OR $=1.36 ; 95 \%$
CI: 1.05-4.8. No significant interaction between age or disc size and the result of MRA analysis arose. AUC of this model was 0.712 (95\% CI: $0.575-0.849)$. Sensitivity is $67.86 \%$; specificity is $74.19 \%$. Nagelkerke $R^{2}$ is $20,02 \%$. Figure 6 presents the ROC curve for this model.

$\mathrm{MOD}-\mathrm{C} 2$ results presents, for another time, that the effect of including the corneal variables increases the diagnostic capacity of GPS alone: OR $=1.63$; 95\% CI: 1.09-3.28. Apart from GPS, other predictors showed discriminating capacity between POAG and normality (Table 2). AUC of this model was 0.838 (95\% CI: 0.736-0.939). Sensitivity is 78.57\%; specificity is $80.65 \%$. Nagelkerke $R^{2}$ is $44,07 \%$. Figure 7 presents the ROC curve for this model.

Table 2 resumes the parameters presented above. 


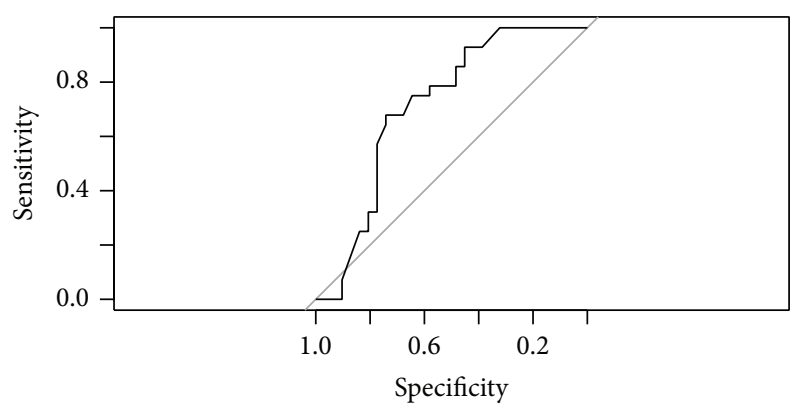

FIgURE 6: ROC curve for model MOD-C1.

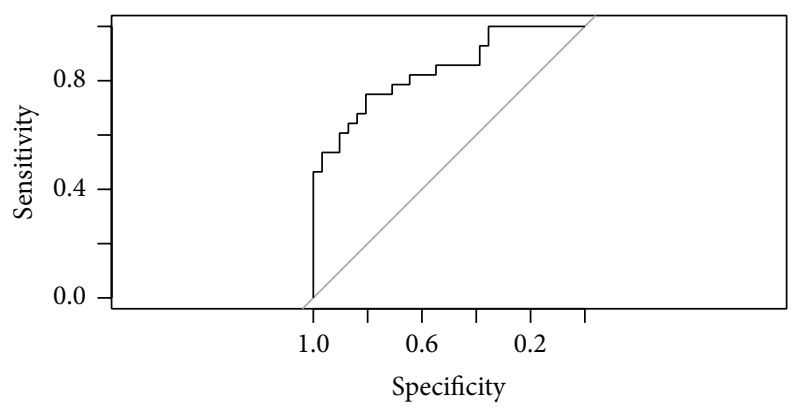

FIGURE 7: ROC curve for model MOD-C2.

Figure 8 presents a comparison of the ROC curves of all the models.

According to a DeLong's test for two correlated ROC curves, a statistically significant difference between AUC of MOD-A1 and MOD-A2 indeed exists $(Z=2.138 ; P=0.032)$; the same occurs between MOD-B1 and MOD-B2 $(Z=1.965$; $P=0.049)$ and between MOD-C1 and MOD-C2 $(Z=2.01$; $P=0.044)$.

According to a logistic univariate regression analysis, the diagnostic accuracy of MOD-Al depends on the stage of glaucoma (Hodapp, Parrish, and Anderson's classification: normality, early stage, and moderate glaucoma) $(\mathrm{OR}=4.21$; 95\% CI: 1.7-12.12). The same phenomenon affects MOD-A2 $(\mathrm{OR}=3.79 ; 95 \% \mathrm{CI}: 1.55-10.69), \mathrm{MOD}-\mathrm{B} 1(\mathrm{OR}=2.44 ; 95 \%$ CI: 1.07-6.08), MOD-B2 (OR = 3.7; 95\% CI: 1.53-10.29), and MOD-C2 (OR = 3.02; 95\% CI: 1.28-8.04). However, the stage of glaucoma did not show a statistically significant influence on MOD-C1 (OR = 1.87; 95\% CI: 0.84-4.51).

\section{Discussion}

Stereoscopic assessment of the optic nerve head by an expert glaucomatologist remains the gold standard for structural glaucoma diagnosis [1-11]. Nevertheless, and despite the former, the accuracy achieved by experts when evaluating $\mathrm{ONH}$ is by far higher than those of general ophthalmologist [1-11] and, what is more, proper glaucoma diagnosis must rely on the $\mathrm{ONH}$ evaluation along with a careful assessment of the visual field, IOP and CCT measurements, and a comprehensive ophthalmic examination [1-11]. Moreover, the access to stereoscopic photography of the $\mathrm{ONH}$ is not always viable in routine clinical practice [1-11].

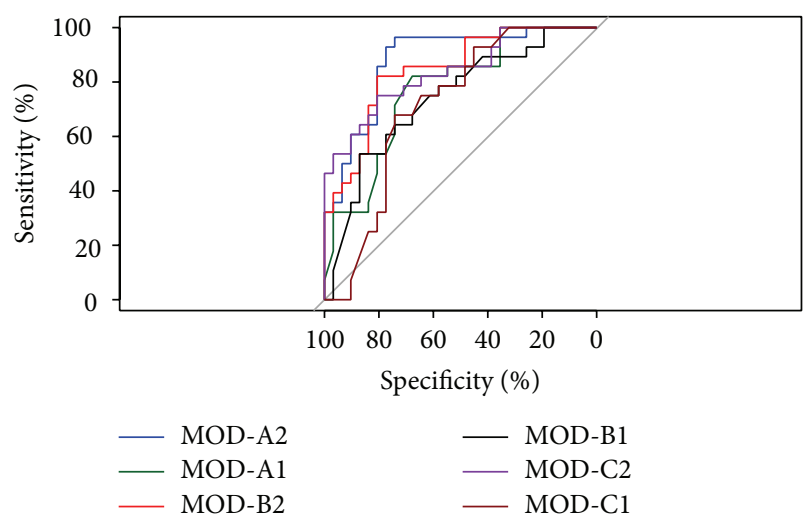

Figure 8: Comparison of ROC curves of all models.

During recent years we have witnessed an impressive technological development in the field of glaucoma structural analysis, which has resulted in many new diagnostic devices, such as the confocal laser ophthalmoscopy (Heidelberg Retina Tomograph) and optical coherence tomography in its various forms. Despite their evident utility, sophisticated analysis software, and flamboyant printouts given by these instruments, none of them provides pathognomonic results $[12,13]$ though their utility as ancillary diagnostic tools has, nowadays, become unquestionable [12-19].

Apart from being an excellent source of imaging of the $\mathrm{ONH}$ (and also the peripapillary RNFL) [20, 21], as a matter of fact, confocal laser scanning ophthalmoscope (Heidelberg Retina Tomograph) has proved to be an outstanding instrument for the diagnosis and follow-up of glaucoma [20]. Sanchez-Galeana et al. [21] reported an overall sensitivity and specificity ranging from $64 \%$ to $75 \%$ and from $68 \%$ to $80 \%$, respectively. Ferreras et al. [22] claimed that the MRA global classification had a sensitivity of $73.9 \%$ and a specificity of 91.5\%, while the GPS global classification had a sensitivity of $58.2 \%$ and a specificity of $94.4 \%$. Ferreras et al. [22] study also put forward that the GPS had slightly higher sensitivity and somewhat lower specificity than the MRA when there was mild damage indicated by visual field tests and that the MRA had the best discrimination capability for moderate and severe glaucoma [22]. They also found that both the GPS and MRA had lower sensitivity and higher specificity for small optic discs $\left(<1.7 \mathrm{~mm}^{2}\right)$ compared with medium and large discs [22]. Nonetheless, the former results are far away from being homogeneous. Thus, Healey et al. [23] reported that the MRA sensitivity was $64.1 \%$, specificity $85.7 \%$, positive predictive value $21 \%$, and negative predictive value $97.6 \%$ for detecting POAG. They also highlighted the interesting fact that including borderline results improved sensitivity (87.0\%) but specificity dropped to $70.6 \%$ [23]. Moreover, as disc size increased, specificity fell, whereas sensitivity, POAG prevalence, and the proportion testing positive rose [23]. Andersson et al. [24] reported that the results of research comparing MRA and GPS are to some extent conflicting, particularly regarding sensitivity. Of all published studies, about $30 \%$ showed significantly or only slightly better sensitivity with MRA, around 50\% indicated better sensitivity with 
GPS, and the remaining 20\% demonstrated similar sensitivity for both methods [24]. Considering specificity, they claimed that a majority of the investigators showed that MRA was superior to GPS [24]. To sum up, a heterogeneous range of results regarding the diagnostic accuracy of the HRT could be found amongst different publications in the literature; however, more or less, the ranges are within the bounds we have quoted before [25-28].

Another issue which concerns the HRT and specifically the MRA is the fact that this test, along with the computing of the stereometric parameters of the $\mathrm{ONH}$, relies on the contour line that must be established subjectively by the examiner himself. A great amount of attention has been paid to this [29-33] and despite the fact that a variation in the positioning of the contour line could have a certain impact on the determination of stereometric and diagnostic parameters, it does not seem to reach great signification. Moreover, the newish version of the HRT (HRT-III) which incorporates the GPS, providing a result independent of the contour line traced by the examiner, which relies on the analysis of the morphometry of the ONH and the peripapillary RNFL, has failed to significantly overtake MRA accuracy [24].

On the other hand, it is a well-known fact that glaucomatous population tends to have thinner corneas. What is more, CCT arises not only as a confounder for IOP measurements, but also as an independent risk factor for glaucoma [2548]. It is somehow astonishing that while great attendance has been given to the analysis of the ONH and RNFL, the studies regarding the corneal structure characteristics inherent to glaucomatous eyes are quite few. In this vein, in several previous studies, we performed a corneal thickness segmentation scheme into virtual circular zones, concentric with the corneal apex, and we analyzed their differences between a sample of healthy volunteers and glaucomatous patients. As many differences arose between both samples, we also studied the diagnostic ability of our virtual segmentation model finding that, without being a diagnostic tool in itself, it showed a nondespicable capacity to discriminate between glaucomatous and healthy eyes [49-53].

Our findings left us with some questions whose answers went far beyond the purposes and capacities of those studies as they go far beyond this one: is there any structural difference between the cornea of glaucomatous eyes and the cornea of healthy eyes? In this case, is this difference primary or does it occur as a consequence of the disease itself? As an answer to the second question, we can say that CCT tends to be a steady parameter along the life of a person [25-53] but, in fact, we still do not have any information about the behaviour of the different corneal zones generated in our segmentation scheme throughout any period of time.

Taking the former into account, the very aim of this clinical study is to determine if adding the variables of the corneal thickness segmentation model to those of the HRT could improve its diagnostic accuracy. Our findings suggest that combining the analysis of both corneal and $\mathrm{ONH}$ structures indeed improves POAG diagnostic capability. To what extent this improvement could have any clinical impact is yet to be established.

\section{Conflict of Interests}

The authors declare that there is no conflict of interests regarding the publication of this paper.

\section{References}

[1] G. L. Spaeth and S. C. Reddy, "Imaging of the optic disk in caring for patients with glaucoma: ophthalmoscopy and photography remain the gold standard," Survey of Ophthalmology, vol. 59, no. 40, pp. 454-458, 2014.

[2] M. Hasanreisoglu, E. Priel, L. Naveh et al., "Digital versus film stereo-photography for assessment of the optic nerve head in glaucoma and glaucoma suspect patients," Journal of Glaucoma, vol. 22, no. 3, pp. 238-242, 2013.

[3] S. Ohkubo, H. Takeda, T. Higashide, T. Sasaki, and K. Sugiyama, "A pilot study to detect glaucoma with confocal scanning laser ophthalmoscopy compared with nonmydriatic stereoscopic photography in a community health screening," Journal of Glaucoma, vol. 16, no. 6, pp. 531-538, 2007.

[4] J. E. Morgan, N. J. L. Sheen, R. V. North et al., "Discrimination of glaucomatous optic neuropathy by digital stereoscopic analysis," Ophthalmology, vol. 112, no. 5, pp. 855-862, 2005.

[5] J. M. Martinez-De-La-Casa, F. Saenz-Frances, A. M. FernandezVidal et al., "Agreement between slit lamp examination and optical coherence tomography in estimating cup-disc ratios," European Journal of Ophthalmology, vol. 18, no. 3, pp. 423-428, 2008.

[6] H. Saito, T. Tsutsumi, A. Iwase, A. Tomidokoro, and M. Araie, "Correlation of disc morphology quantified on stereophotographs to results by Heidelberg Retina Tomograph II, GDx variable corneal compensation, and visual field tests," Ophthalmology, vol. 117, no. 2, pp. 282-289, 2010.

[7] N. J. Reus, H. G. Lemij, D. F. Garway-Heath et al., "Clinical assessment of stereoscopic optic disc photographs for glaucoma: the European Optic Disc Assessment Trial," Ophthalmology, vol. 117, no. 4, pp. 717-723, 2010.

[8] R. Varma, W. C. Steinmann, and I. U. Scott, "Expert agreement in evaluating the optic disc for glaucoma," Ophthalmology, vol. 99, no. 2, pp. 215-221, 1992.

[9] N. J. Reus, M. de Graaf, and H. G. Lemij, "Accuracy of GDx VCC, HRT I, and clinical assessment of stereoscopic optic nerve head photographs for diagnosing glaucoma," British Journal of Ophthalmology, vol. 91, no. 3, pp. 313-318, 2007.

[10] L. S. Abrams, I. U. Scott, G. L. Spaeth, H. A. Quigley, and R. Varma, "Agreement among optometrists, ophthalmologists, and residents in evaluating the optic disc for glaucoma," Ophthalmology, vol. 101, no. 10, pp. 1662-1667, 1994.

[11] Y.-W. Lan, D. B. Henson, and A. J. Kwartz, "The correlation between optic nerve head topographic measurements, peripapillary nerve fibre layer thickness, and visual field indices in glaucoma," British Journal of Ophthalmology, vol. 87, no. 9, pp. 1135-1141, 2003.

[12] N. Venugopal, G. Kummararaj, S. Kummararaj, and B. Bharathi, "Structural-functional dissociation in glaucoma: an attempt to end controversy," Indian Journal of Ophthalmology, vol. 61, no. 9, pp. 532-533, 2013.

[13] C. Garudadri, S. Senthil, and H. Rao, "Evidence-based approach to glaucoma management," Indian Journal of Ophthalmology, vol. 59, no. 1, pp. S5-S10, 2011.

[14] N. Medved and B. Cvenkel, "Diagnostic accuracy of the Moorfields Regression Analysis using the Heidelberg Retina 
Tomograph in glaucoma patients with visual field defects," European Journal of Ophthalmology, vol. 17, no. 2, pp. 216-222, 2007.

[15] A. J. Tatham, R. N. Weinreb, and F. A. Medeiros, "Strategies for improving early detection of glaucoma: the combined structure-function index," Clinical Ophthalmology, vol. 8, pp. 611-621, 2014.

[16] G. Vizzeri, S. Kjaergaard, H. Rao, and L. Zangwill, "Role of imaging in glaucoma diagnosis and follow-up," Indian Journal of Ophthalmology, vol. 59, no. 1, pp. S59-S68, 2011.

[17] D. S. Greenfield, "Optic nerve and retinal nerve fiber layer analyzers in glaucoma," Current Opinion in Ophthalmology, vol. 13, no. 2, pp. 68-76, 2002.

[18] P. Sharma, P. A. Sample, L. M. Zangwill, and J. S. Schuman, "Diagnostic tools for glaucoma detection and management," Survey of Ophthalmology, vol. 53, no. 6, supplement 1, pp. S17S32, 2008.

[19] S. C. Lin, K. Singh, H. D. Jampel et al., "Optic nerve head and retinal nerve fiber layer analysis: a report by the American Academy of Ophthalmology," Ophthalmology, vol. 114, no. 10, pp. 1937-1949, 2007.

[20] J. E. DeLeón-Ortega, S. N. Arthur, G. McGwin Jr., A. Xie, B. E. Monheit, and C. A. Girkin, "Discrimination between glaucomatous and nonglaucomatous eyes using quantitative imaging devices and subjective optic nerve head assessment," Investigative Ophthalmology and Visual Science, vol. 47, no. 8, pp. 3374-3380, 2006.

[21] C. Sanchez-Galeana, C. Bowd, E. Z. Blumenthal, P. A. Gokhale, L. M. Zangwill, and R. N. Weinreb, "Using optical imaging summary data to detect glaucoma," Ophthalmology, vol. 108, no. 10, pp. 1812-1818, 2001.

[22] A. Ferreras, A. B. Pajarín, V. Polo, J. M. Larrosa, L. E. Pablo, and F. M. Honrubia, "Diagnostic ability of Heidelberg Retina Tomograph 3 classifications: glaucoma probability score versus Moorfields regression analysis," Ophthalmology, vol. 114, no. 11, pp. 1981.el-1987.e1, 2007.

[23] P. R. Healey, A. J. Lee, T. Aung, T. Y. Wong, and P. Mitchell, "Diagnostic accuracy of the Heidelberg Retina Tomograph for glaucoma: a population-based assessment," Ophthalmology, vol. 117, no. 9, pp. 1667-1673, 2010.

[24] S. Andersson, A. Heijl, and B. Bengtsson, "Optic disc classification by the Heidelberg Retina Tomograph and by physicians with varying experience of glaucoma," Eye, vol. 25, no. 11, pp. 1401-1407, 2011.

[25] N. Harizman, J. R. Zelefsky, E. Ilitchev, C. Tello, R. Ritch, and J. M. Liebmann, "Detection of glaucoma using operatordependent versus operator-independent classification in the Heidelberg retinal tomograph-III," British Journal of Ophthalmology, vol. 90, no. 11, pp. 1390-1392, 2006.

[26] A. Coops, D. B. Henson, A. J. Kwartz, and P. H. Artes, "Automated analysis of Heidelberg retina tomograph optic disc images by glaucoma probability score," Investigative Ophthalmology and Visual Science, vol. 47, no. 12, pp. 5348-5355, 2006.

[27] M. Iester, F. S. Mikelberg, and S. M. Drance, "The effect of optic disc size on diagnostic precision with the Heidelberg retina tomograph," Ophthalmology, vol. 104, no. 3, pp. 545-548, 1997.

[28] L. M. Zangwill, C. Bowd, C. C. Berry et al., "Discriminating between normal and glaucomatous eyes using the Heidelberg Retina Tomograph, GDx Nerve Fiber Analyzer, and Optical Coherence Tomograph," Archives of Ophthalmology, vol. 119, no. 7, pp. 985-993, 2001.
[29] M. Iester, V. Mariotti, F. Lanza, and G. Calabria, “The effect of contour line position on optic nerve head analysis by Heidelberg Retina Tomograph," European Journal of Ophthalmology, vol. 19, no. 6, pp. 942-948, 2009.

[30] W. V. Hatch, J. G. Flanagan, D. E. Williams-Lyn, Y. M. Buys, T. Farra, and G. E. Trope, "Interobserver agreement of Heidelberg retina tomograph parameters," Journal of Glaucoma, vol. 8, no. 4, pp. 232-237, 1999.

[31] J. S. Schuman, G. Wollstein, T. Farra et al., "Comparison of optic nerve head measurements obtained by optical coherence tomography and confocal scanning laser ophthalmoscopy," American Journal of Ophthalmology, vol. 136, no. 2, pp. 504-512, 2003.

[32] S. Miglior, E. Albé, M. Guareschi, L. Rossetti, and N. Orzalesi, "Intraobserver and interobserver reproducibility in the evaluation of optic disc stereometric parameters by Heidelberg Retina Tomograph," Ophthalmology, vol. 109, no. 6, pp. 10721077, 2002.

[33] Y.-B. Liang, X. Liu, Y.-L. Ling, J.-J. Huang, and X.-P. Zheng, "Study of agreement of optic nerve head topography parameters," Zhonghua yan ke za zhi, vol. 39, no. 8, pp. 471-475, 2003.

[34] L. Coman, M. Costescu, M. Alecu, and O. A. Coman, "Correlation between corneal thickness and optic disc morphology in normal tension glaucoma using modern technical analysis," Romanian Journal of Morphology and Embryology, vol. 55, no. 3, pp. 857-862, 2014.

[35] A. Ghanem and T. Mokbel, "Correlation of central corneal thickness and optic nerve head topography in patients with primary open-angle glaucoma," Oman Journal of Ophthalmology, vol. 3, no. 2, pp. 75-80, 2010.

[36] M. O. Gordon, J. A. Beiser, J. D. Brandt et al., “The ocular hypertension treatment study: baseline factors that predict the onset of primary open-angle glaucoma," Archives of Ophthalmology, vol. 120, no. 6, pp. 714-720, 2002, discussion 829-30.

[37] E. N. Vithana, T. Aung, C. C. Khor et al., "Collagen-related genes influence the glaucoma risk factor, central corneal thickness," Human Molecular Genetics, vol. 20, no. 4, pp. 649-658, 2011.

[38] T. Eysteinsson, F. Jonasson, H. Sasaki et al., "Central corneal thickness, radius of the corneal curvature and intraocular pressure in normal subjects using non-contact techniques: Reykjavik eye study," Acta Ophthalmologica Scandinavica, vol. 80, no. 1, pp. 11-15, 2002.

[39] T. Toh, S. H. M. Liew, J. R. MacKinnon et al., "Central corneal thickness is highly heritable: the twin eye studies," Investigative Ophthalmology and Visual Science, vol. 46, no. 10, pp. 3718-3722, 2005.

[40] F. A. Medeiros, P. A. Sample, L. M. Zangwill, C. Bowd, M. Aihara, and R. N. Weinreb, "Corneal thickness as a risk factor for visual field loss in patients with preperimetric glaucomatous optic neuropathy," American Journal of Ophthalmology, vol. 136, no. 5, pp. 805-813, 2003.

[41] L. W. Herndon, J. S. Weizer, and S. S. Stinnett, "Central corneal thickness as a risk factor for advanced glaucoma damage," Archives of Ophthalmology, vol. 122, no. 1, pp. 17-21, 2004.

[42] N. G. Congdon, A. T. Broman, K. Bandeen-Roche, D. Grover, and H. A. Quigley, "Central corneal thickness and corneal hysteresis associated with glaucoma damage," American Journal of Ophthalmology, vol. 141, no. 5, pp. 868-875, 2006.

[43] M. C. Leske, A. Heijl, L. Hyman et al., "Predictors of long-term progression in the early manifest glaucoma trial," Ophthalmology, vol. 114, no. 11, pp. 1965-1972, 2007. 
[44] European Glaucoma Prevention Study (EGPS) Group, S. Miglior, N. Pfeiffer et al., "Predictive factors for open-angle glaucoma among patients with ocular hypertension in the European glaucoma prevention study," Ophthalmology, vol. 114, no. 1, pp. 3-9, 2007.

[45] P. Tsikripis, D. Papaconstantinou, C. Koutsandrea, M. Apostolopoulos, and I. Georgalas, "The effect of prostaglandin analogs on the biomechanical properties and central thickness of the cornea of patients with open-angle glaucoma: a 3-year study on 108 eyes," Drug Design, Development and Therapy, vol. 7, pp. 1149-1156, 2012.

[46] M. M. Whitacre, R. A. Stein, and K. Hassanein, "The effect of corneal thickness on applanation tonometry," American Journal of Ophthalmology, vol. 115, no. 5, pp. 592-596, 1993.

[47] P.-A. Tonnu, T. Ho, T. Newson et al., "The influence of central corneal thickness and age on intraocular pressure measured by pneumotonometry, non-contact tonometry, the Tono-Pen XL, and Goldmann applanation tonometry," British Journal of Ophthalmology, vol. 89, no. 7, pp. 851-854, 2005.

[48] M. Kohlhaas, A. G. Boehm, E. Spoerl, A. Pürsten, H. J. Grein, and L. E. Pillunat, "Effect of central corneal thickness, corneal curvature, and axial length on applanation tonometry," Archives of Ophthalmology, vol. 124, no. 4, pp. 471-476, 2006.

[49] F. Saenz-Frances, J. Garcia-Feijó, L. Jañez et al., "Comparing corneal variables in healthy subjects and patients with primary open-angle glaucoma," Investigative Ophthalmology \& Visual Science, vol. 52, no. 6, pp. 3683-3688, 2011.

[50] F. Saenz-Frances, L. Jañez, L. Borrego-Sanz et al., "Effect of corneal morphometry on dynamic contour and goldmann applanation tonometry," Journal of Glaucoma, vol. 22, no. 5, pp. 380-383, 2013.

[51] F. Saenz-Frances, E. Gonzalez-Pastor, L. Borrego-Sanz et al., "Comparing central corneal thickness measured using ultrasound pachymetry and the Pentacam in healthy subjects and patients with primary open-angle glaucoma," Journal Francais d'Ophtalmologie, vol. 35, no. 5, pp. 333-337, 2012.

[52] F. Sáenz-Francés, R. García-Catalán, M. Jerez-Fidalgo et al., "Comparison of Goldmann applanation and dynamic contour tonometry measurements: effects of corneal morphometry," Archivos de la Sociedad Española de Oftalmología, vol. 86, no. 9, pp. 287-291, 2011.

[53] F. Saenz-Frances, L. Jañez, L. Borrego-Sanz et al., "Characterization of the thickness of different corneal zones in glaucoma: effect on dynamic contour, Goldmann and rebound tonometries," Acta Ophthalmologica, vol. 91, no. 8, pp. e620-e627, 2013. 


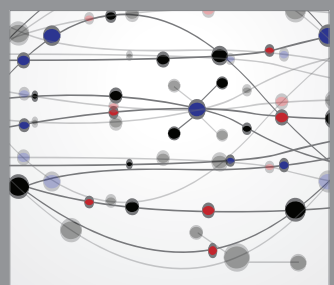

The Scientific World Journal
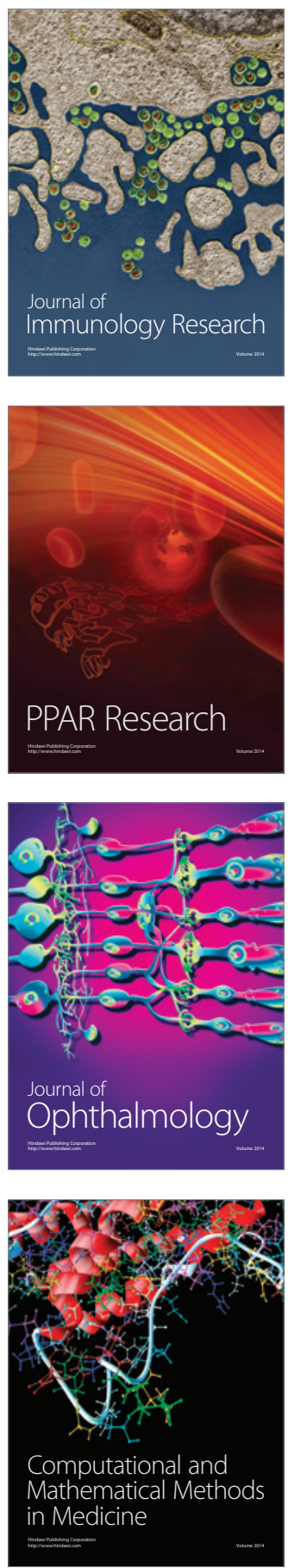

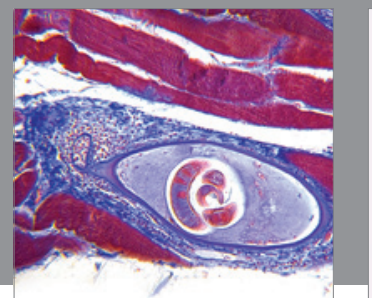

Gastroenterology

Research and Practice
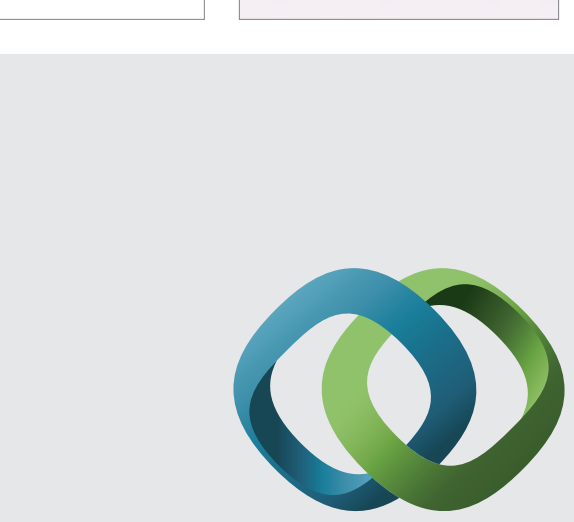

\section{Hindawi}

Submit your manuscripts at

http://www.hindawi.com
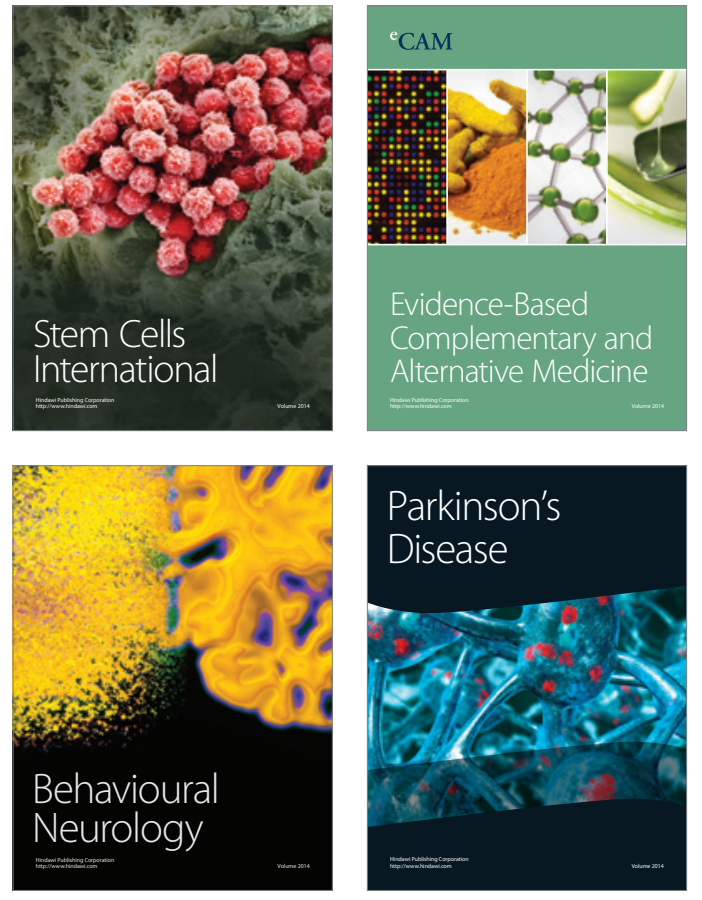
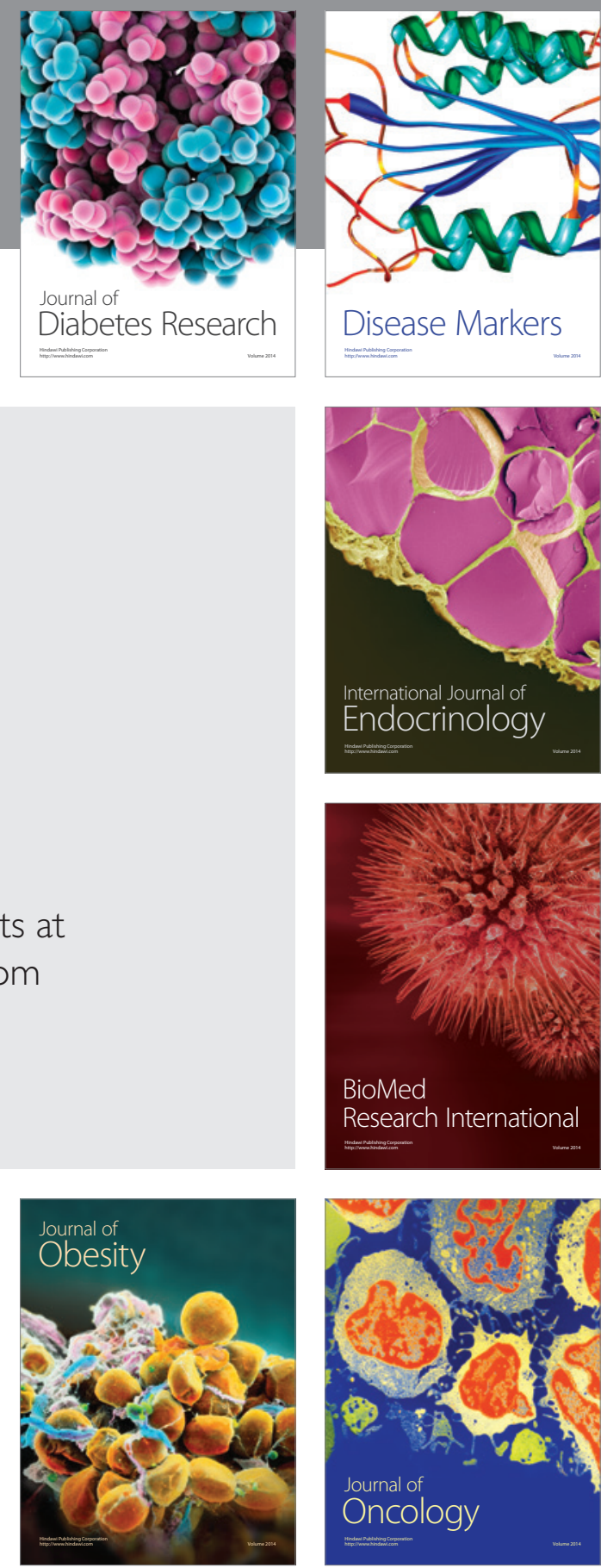

Disease Markers
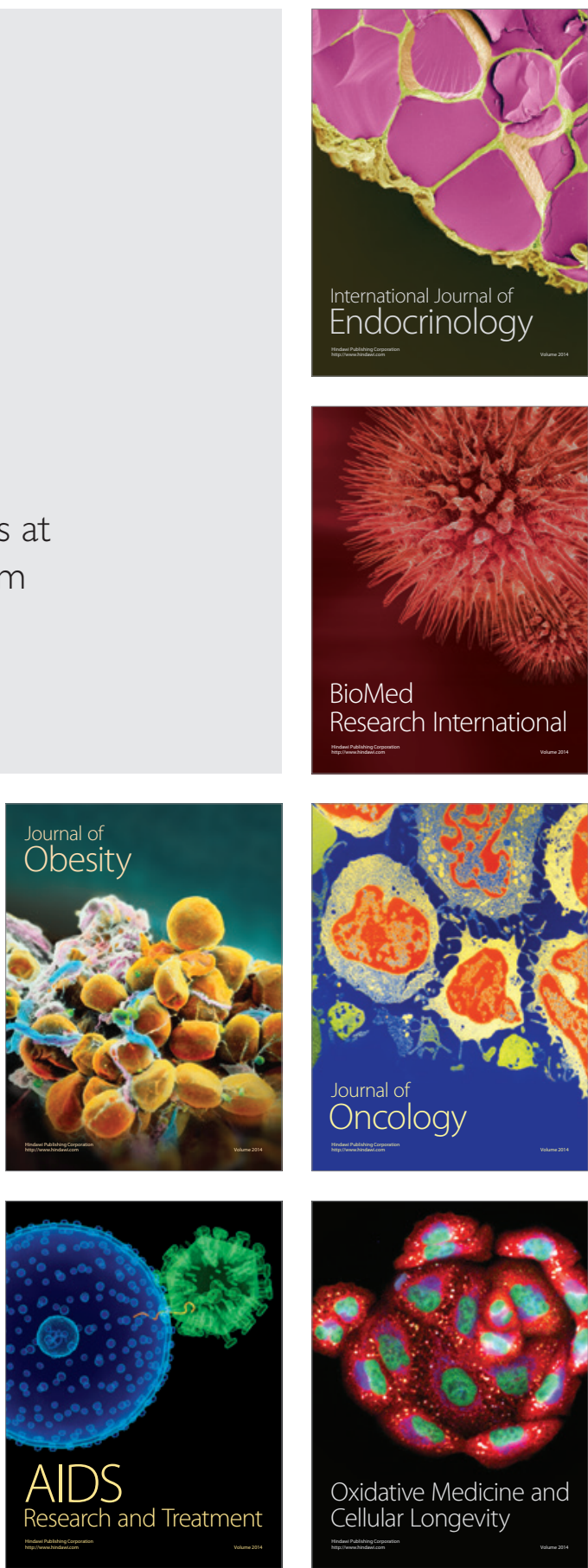